C2003 IEEE. Personal use of this material is permitted. However, permission to reprint/republish this material for advertising or promotional purposes or for creating new collective works for resale or redistribution to servers or lists, or to reuse any copyrighted component of this work in other works must be obtained from the IEEE. 


\title{
Adoption of Collaboration Information Technologies in Australian and US Organizations: A Comparative Study
}

\author{
Deepinder S. Bajwa \\ Department of Decision Sciences, Western Washington University, Bellingham, WA 98225 \\ deepinder.bajwa@wwu.edu \\ L. Floyd Lewis \\ Department of Decision Sciences, Western Washington University, Bellingham, WA 98225 \\ floyd.lewis@wwu.edu \\ Graham Pervan \\ School of Information Systems, Curtin Business School, Curtin University, Perth, Australia \\ pervanG@cbs.curtin.edu.au
}

\begin{abstract}
Collaboration to accomplish tasks has taken on a new meaning over the past few years. The majority of organizations are viewing information technology (IT) as a key enabler to transcend time and distance barriers to collaborate efficiently and effectively. Despite this, we know very little about the macro level adoption of IT to support collaboration. This paper assesses the pattern of adoption of seven IT clusters to support task-oriented collaboration in US and Australian organizations. Data collected from one hundred and forty Australian organizations and one hundred and nineteen US organizations is analyzed to compare adoption patterns. Our results suggest that stand-alone e-mail systems, audio teleconferencing systems, and videoconferencing are the most widely adopted technologies to support collaboration in both countries while web-based tools and electronic meeting systems are the least commonly adopted. A further analysis of data suggests that promotion of collaboration, mode of collaboration, and the adoption of some IT clusters are affected by region. Implications of these findings are discussed along with some directions for practice and research.
\end{abstract}

\section{Introduction}

Although the majority of modern organizations depend upon groups to accomplish tasks, collaboration amongst work group members can be challenging, especially in distributed environments. Fortunately, information and networking technologies may help provide a solution for group members in organizations who want to collaborate on tasks effectively and efficiently irrespective of time and distance barriers. Many organizations are successfully deploying IT to support collaboration between dispersed work groups [5]. Despite these trends, there have been no large-scale investigations on the pattern of adoption of IT solutions that have the capability to support task-oriented group collaboration.

We attempt to fill that void by focusing on the patterns of organizational adoption of IT to support task-oriented collaborative work. While our efforts continue to collect data on a global basis, here we report on our research conducted in Australia and the US. The ITs investigated in this study include: Stand-alone e-mail systems, audio teleconferencing, videoconferencing, dataconferencing, web-based tools, proprietary groupware technology, and electronic meetings systems (EMS). While some of these technologies to support group work have been around for nearly two decades, others are somewhat recent developments. Studies have investigated general adoption of individual technologies like e-mail [10], web groupware [7], proprietary groupware [18], and EMS [13][19]. However, no prior research has attempted a large-scale investigation to explore adoption patterns specifically to support task-oriented collaboration across multiple technologies. Such insights are important to inform IT practices as well as research and development efforts so that IT can better support task-oriented collaboration amongst group members.

This paper makes three key contributions to existing research on collaboration. First, it sheds light on the pattern of adoption of IT to specifically support taskoriented collaboration in Australian and US organizations. Second, it provides insights into the promotion of collaboration in Australian and US organizations. Third, it documents the availability of IT support for several collaboration scenarios in Australian and US organizations. In particular, we address the following research questions. 
- Is collaboration being promoted widely in Australian and US organizations? Are there any differences in promotion of collaboration between Australian and US organizations?

- To what extent is IT being used to support various Time / Place collaboration scenarios in Australian and US organizations? Does this vary by region (country)?

- What is the pattern of adoption of seven ITs in supporting collaboration in Australian and US organizations? Does adoption vary by region (country)?

As the study is exploratory in nature, we do not propose any hypotheses for validation. The rest of the paper is organized as follows. The next section briefly discusses the role of IT in task-oriented collaboration. We then describe the empirical study methodology. This followed by analysis of data. In the last section, we discuss our results, address the limitations of our study, and present the implications for practice and future research.

\section{Deploying IT to support collaboration}

The importance of the role of IT in distributed group process or in collaboration has been strongly reinforced by researchers [20]. While a multitude of IT solutions can be deployed to support collaboration, it has been urged that research be undertaken to study distributed groups using a combination of communication technologies [20]. This parallels the conventional wisdom that alternative communication channels for group collaboration are important and required [21].

The notion of deploying IT to enhance task-oriented collaboration amongst work groups is not new. In fact, according to Jessup and Valacich [9, pp. 245] there are "dozens of books and hundreds of research articles published in the areas of group support systems, computer supported cooperative work, distributed learning..." that have focused on IT support for task collaboration in distributed environments. It is commonly known that various ITs like e-mail, teleconferencing (audio), videoconferencing, and dataconferencing can greatly enhance group collaboration [12]. The use of such technologies to collaborate on tasks in distributed environments has been well publicized. Research on the popularity and use of other technologies like proprietary groupware systems [8][11], Web-based tools [1][6][14][22], and Electronic Meeting Systems (EMS) [15] to support group work has also been well documented.

While there is little doubt that a variety of ITs have the capability to lend some type of support in taskoriented collaboration, different approaches may have different capacities to process rich information. Information richness is the "ability of information to change understanding within a time interval" $[4, \mathrm{pp}$. 560]. Since group tasks often vary, it is plausible that there is no single preferred IT that should be selected to support all types of task-oriented collaboration. A combination of several ITs might be appropriate in many circumstances, especially for important or complicated exchanges of information. In general, the choice of such technologies may depend upon the amount of information required, the time requirement for information (how fast is it required), the effectiveness of communication required, and the efficiency of communication required [3].

Our own experience also suggests that multiple channels for communication and coordination are critical in task-oriented collaboration. Given the scarcity of empirical research exploring the multiple adoption of ITs in supporting task-oriented collaboration, a large-scale study was undertaken in 2001. The next section describes the study methodology.

\section{Study methodology}

Based upon the past literature, seven different information technologies that have the capability to support collaboration amongst work groups were identified. Examples of specific products for each of the seven technologies were also identified to guide responses during data collection. These were:

- E-mail e.g., Pegasus mail, Microsoft Outlook, Hotmail, etc.

- Teleconferencing (two-way audio) e.g., NetMeeting, CU-SeeMe, etc.

- Videoconferencing (two-way audio and video) e.g., NetMeeting, CU-SeeMe, etc

- Dataconferencing (whiteboards, application sharing, data presentations) e.g., NetMeeting, Evoke, WebEx, etc.

- Web-based Collaborative Tools (Intranets, Listservs, Newsgroups, chat, message boards) e.g., E-groups, Yahoo Groups, Open Topics, etc.

- Proprietary Groupware Tools (with or without web browser interface) e.g., Lotus Notes, IBM Workgroup, ICL TeamWARE Office, Novell Groupwise, The Groove, etc.

- Electronic Meeting Systems e.g., GroupSystems, MeetingWorks, TeamFocus, VisionQuest, Facilitate.com, etc.

A three-phase instrument development process was undertaken along the guidelines proposed by Sethi and King [17]. In the first phase, an extensive review of the literature was conducted to formulate item measures for variables under investigation. In the second phase, the 
formulated item-measures were then reviewed by researchers that have been active in conducting research on workgroup collaboration for over two decades. In the final phase, the measures were pilot tested by soliciting comments from an executive director of the Society for Information Management (SIM) and a past CIO of a Fortune 500 organization. Both the participants were asked to comment on the clarity of the item-measures and appropriateness of the IT clusters to support task-oriented collaboration. Based upon their feedback, appropriate modifications were made. The resulting questionnaire was then used to collect the data in US and Australia.

While the overall study had a much broader purpose, here we will focus on only those variables that are appropriate to the scope of this paper. These include: promotion of collaboration, collaboration scenarios, and adoption of IT clusters supporting task-oriented collaboration.

Promotion of Collaboration was measured using four items. Two of these items focused on top management effort to promote intra-organization and interorganization collaboration, the third item measured the use of virtual teams for collaboration, and the fourth item focused on the existence of a person with responsibility to manage and promote overall collaboration efforts in the organization. While no previous measures for promotion of collaboration were available, the four items were formulated based upon the suggestion of the pilot study participants and our own understanding of collaboration promotion in organizations. A five-point scale (strongly disagree, disagree, neutral, agree, strongly agree) was used for each of the four items.

Level of Access (adoption) status for each IT cluster was measured by a single item that required respondents to indicate whether the specific IT cluster was accessible and available to end-users in their organization. A fivepoint scale anchored at the extremes and mid-way $(1=$ no one in the organization, $3=$ some persons in the organization, and $5=$ everyone in the organization) was used for each of the seven IT clusters.

Data was first collected in the US using an electronic mailing to the members of SIM. An e-mail message along with an electronic link to a server was sent to all the members of SIM. The message explained the purpose of the study and asked for their cooperation in responding to the survey. Each member was requested to forward the message to the appropriate person if they were not knowledgeable about IT support for taskoriented collaboration in their respective organization. A follow-up e-mail message was sent after seven working days.

The study was then extended to Australian organizations. A mailing list of the largest 1,000 organizations (measured by Gross Revenue in the
2000/2001 financial year) in Australia was used to collect data in the follow-up study. This list, the "BRW Top 1000 ", is developed by Australia's leading business magazine, the Business Review Weekly (BRW), and was purchased from BRW (BRW, 2001). In addition to the mailing list, a database containing summary financial and other data about each organization was also obtained. This data included (publicly available) information on Gross Revenue, Total Assets, Profit, Number of Employees, Organization Type, Industry, and Location of Corporate Headquarters. The financial information was also augmented with the corresponding rank in the Top 1000 for that organization.

A target sample of 500 randomly selected organizations from the Top 1000 was used to collect data in Australia. The selection process was simply to work through the mailing list in rank order (the rank being based on 2000/2001 Gross Revenue) from number 1 while following the sequence of numbers from a standard random number table. If the random number was odd then the organization was included in the target sample. This was done until 500 organizations had been selected.

The same questionnaire that was administered in the US study was then mailed to the 500 chosen organizations, addressed to the most senior IT person in the organization (unfortunately, the BRW list did not include email addresses). In addition to the questionnaire, a brief cover letter and a reply-paid envelope were included in the package. Since the information sought was not particularly sensitive and, as mentioned above, the researchers had obtained a database of information about each organization from BRW, it was decided that the reply-paid envelopes would be identified with the organization's Top 1000 rank. This enabled the researchers to include in the analysis some of the data mentioned above on each organization without having to burden the respondent with the task of recalling and providing these organizational details themselves. In the cover letter it was explained that the organizations were being identified in this way so that it could save the respondents from further effort in providing the extra data, but that they would not be identified in any way in the analysis and publication of results (i.e., that their individual responses would be kept completely confidential). Only three of the responding organizations chose not to be identified in this way.

\section{Response profile}

One hundred and nineteen usable responses were received from US organizations and one hundred and forty usable responses from Australian organizations. Almost all of the respondents indicated their position or 
title. Based upon their responses, they were grouped under top, middle, and lower/other tier. The top tier consisted mainly of responses from the CEO, President, Executive VP, Managing Director, CFO, CIO and other Executive Managers. Responses from IS/IT Directors, IS Senior Managers, IS/IT Managers, and other Functional Managers were grouped in the second tier, while the remaining were categorized in the third tier.

Figure 1 compares the position of the respondents in Australian and US organizations. The majority of the Australian respondents belonged to the middle tier $(75.7 \%)$ while responses received from US organizations were almost evenly split between top tier $(47.9 \%)$ and middle tier $(49.6 \%)$ positions. Very few respondents held lower tier positions. Figure 2 compares the percentages of responses from organizations of various sizes (number of employees) in Australia and the US. The responses included organizations of all sizes. However, the majority of the responses are from mid-sized and large organizations. A comparison with the US responses reveals that the US sample has more organizations in the largest category (more than 10,000 employees). So, even though the sample is from Australia's largest 1,000 organizations, US organizations often tend to be much bigger than organizations in other industrialized nations. Figure 3 shows percentages of responses for the total number of IT employees in each of the responding organizations in Australia and US. Once again, small as well as large IT functions are represented in the responses. However, the general pattern suggests that many Australian IT functions are smaller than their US counterparts. This may reflect that many Australian organizations are foreign-owned $(25 \%$ in the Australian sample were foreign-owned) which may mean they receive major IT support from corporate IT functions located at headquarters overseas. Also the popularity of IT outsourcing in large Australian organizations may result in small IT departments within organizations [16].
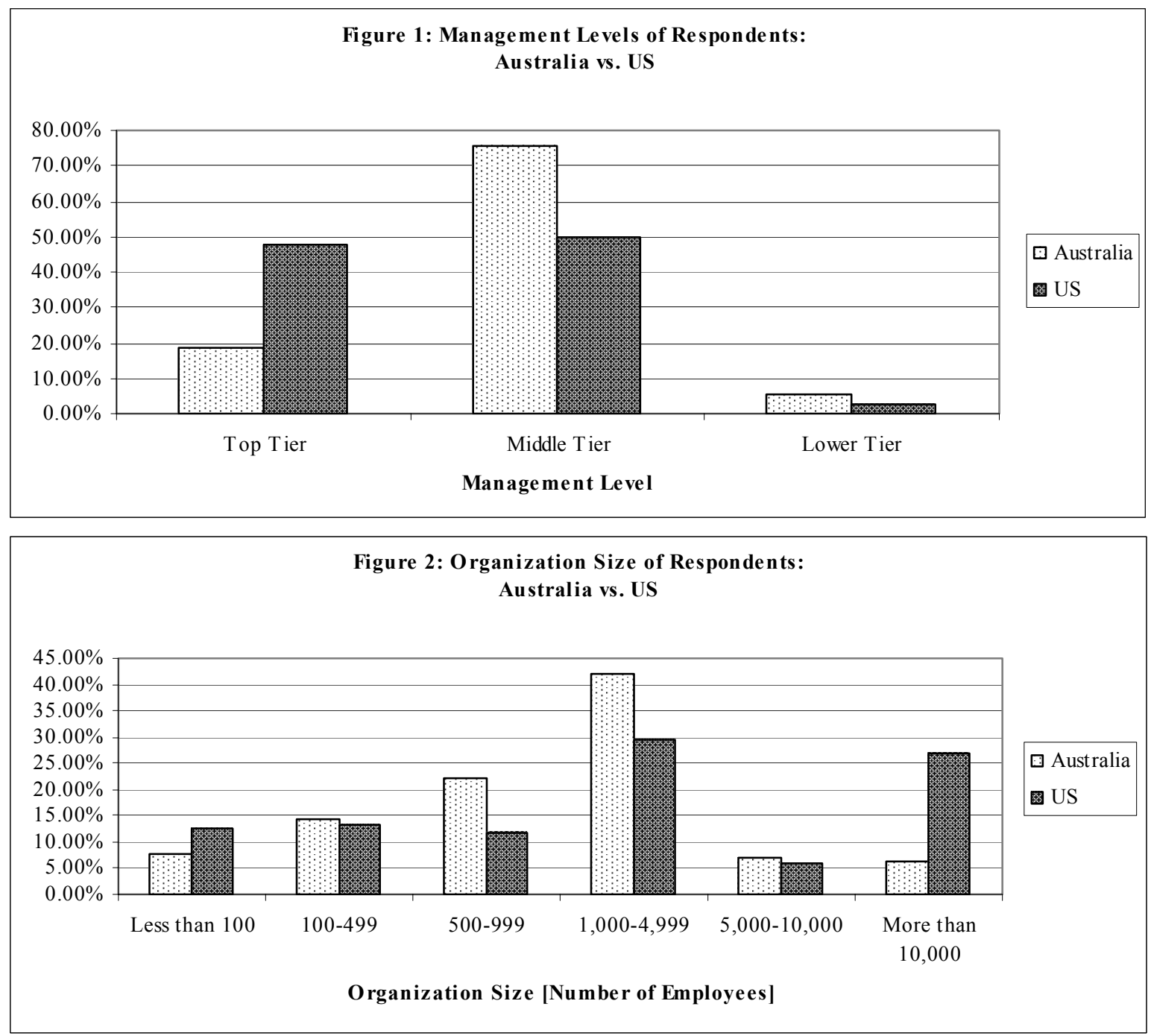


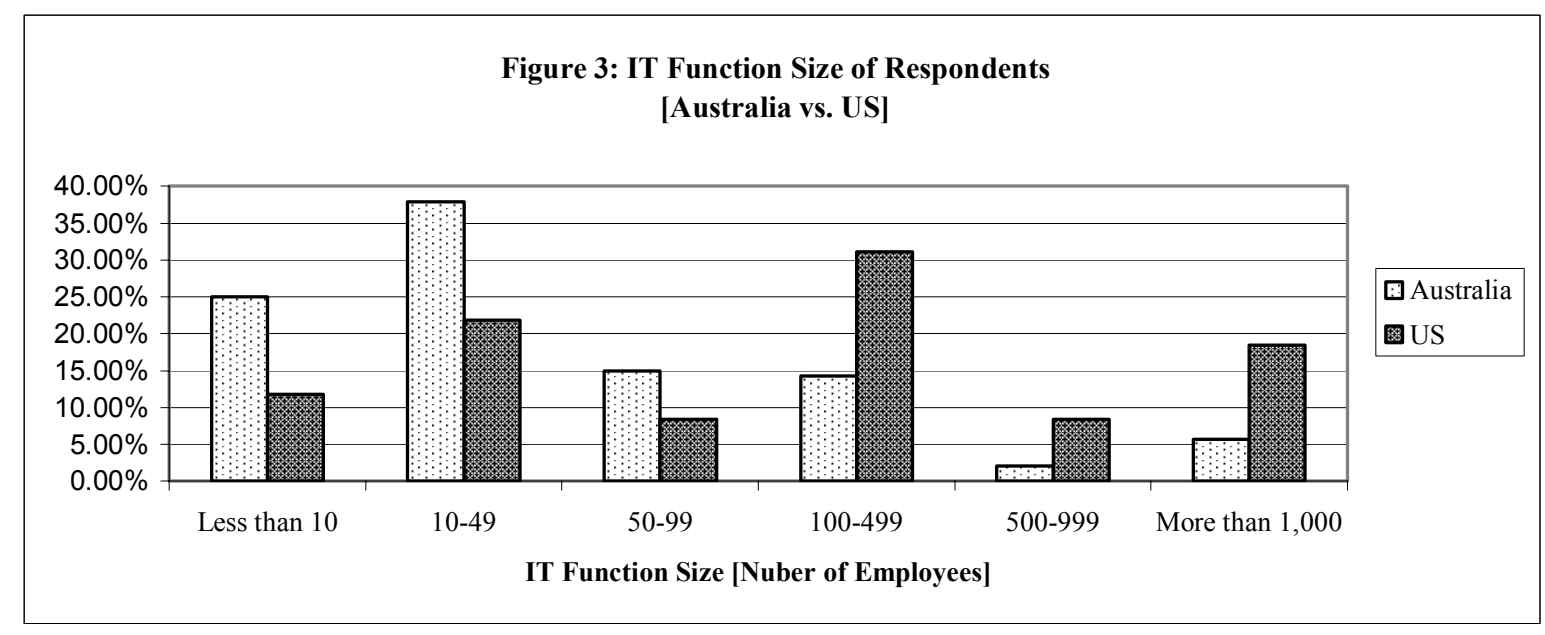

\section{Data analysis}

Two primary data analysis techniques were deployed. For variables using interval scales, ANOVA was used for comparison between Australian and US organizations. For categorical variables, Chi-square analysis was used to make comparisons.

Table 1 reports the results of ANOVA comparing collaboration of promotion means between Australian and US organizations. Both item level and construct level comparisons are included. The majority of the means (item and construct) are above the average for the scale (i.e. greater than 3). There were significant differences in three of the four collaboration item means and overall promotion of collaboration between
Australian and US organizations, with US means generally higher. Figure 4 shows IT support for the four Time / Place collaboration scenarios while table 2 shows the results of Chi-square analysis of IT support for the collaboration scenarios across region (country). IT support for all modes of collaboration are popular in both, Australian and US organizations. There were significant differences in the proportion of organizations providing IT support to collaborate at the Same Time / Same Place, Same Time / Different Place, and Different Time / Different Place between Australian and US organizations, with greater proportion of US organizations providing such support.

Table 1: Comparison of Collaboration of Promotion Means

\begin{tabular}{|c|c|c|c|c|c|c|}
\hline $\begin{array}{l}\text { Collaboration } \\
\text { Items/Construct }\end{array}$ & Country & $\mathbf{N}$ & Mean & SD & $\mathbf{F}$ & Sig. \\
\hline \multirow{2}{*}{$\begin{array}{l}\text { Intra-organization } \\
\text { Collaboration }\end{array}$} & Australia & 138 & 3.73 & 1.04 & \multirow[t]{2}{*}{7.90} & \multirow[t]{2}{*}{$0.005^{* *}$} \\
\hline & US & 116 & 4.07 & 0.83 & & \\
\hline \multirow{2}{*}{$\begin{array}{l}\text { Inter-organization } \\
\text { Collaboration }\end{array}$} & Australia & 138 & 3.38 & 1.02 & \multirow[t]{2}{*}{9.10} & \multirow[t]{2}{*}{$0.003^{* *}$} \\
\hline & US & 117 & 3.74 & 0.90 & & \\
\hline \multirow[t]{2}{*}{ Use of Virtual Teams } & Australia & 138 & 3.01 & 1.14 & \multirow[t]{2}{*}{8.74} & \multirow[t]{2}{*}{$0.003 * *$} \\
\hline & US & 117 & 3.43 & 1.12 & & \\
\hline \multirow{2}{*}{$\begin{array}{l}\text { Collaboration } \\
\text { Responsibility }\end{array}$} & Australia & 138 & 2.33 & 1.26 & \multirow[t]{2}{*}{0.11} & \multirow[t]{2}{*}{0.74} \\
\hline & US & 117 & 2.38 & 1.22 & & \\
\hline \multirow[t]{2}{*}{ Overall Collaboration } & Australia & 138 & 3.11 & 0.83 & \multirow[t]{2}{*}{8.76} & \multirow[t]{2}{*}{$0.003 * *$} \\
\hline & US & 117 & 3.40 & 0.72 & & \\
\hline
\end{tabular}




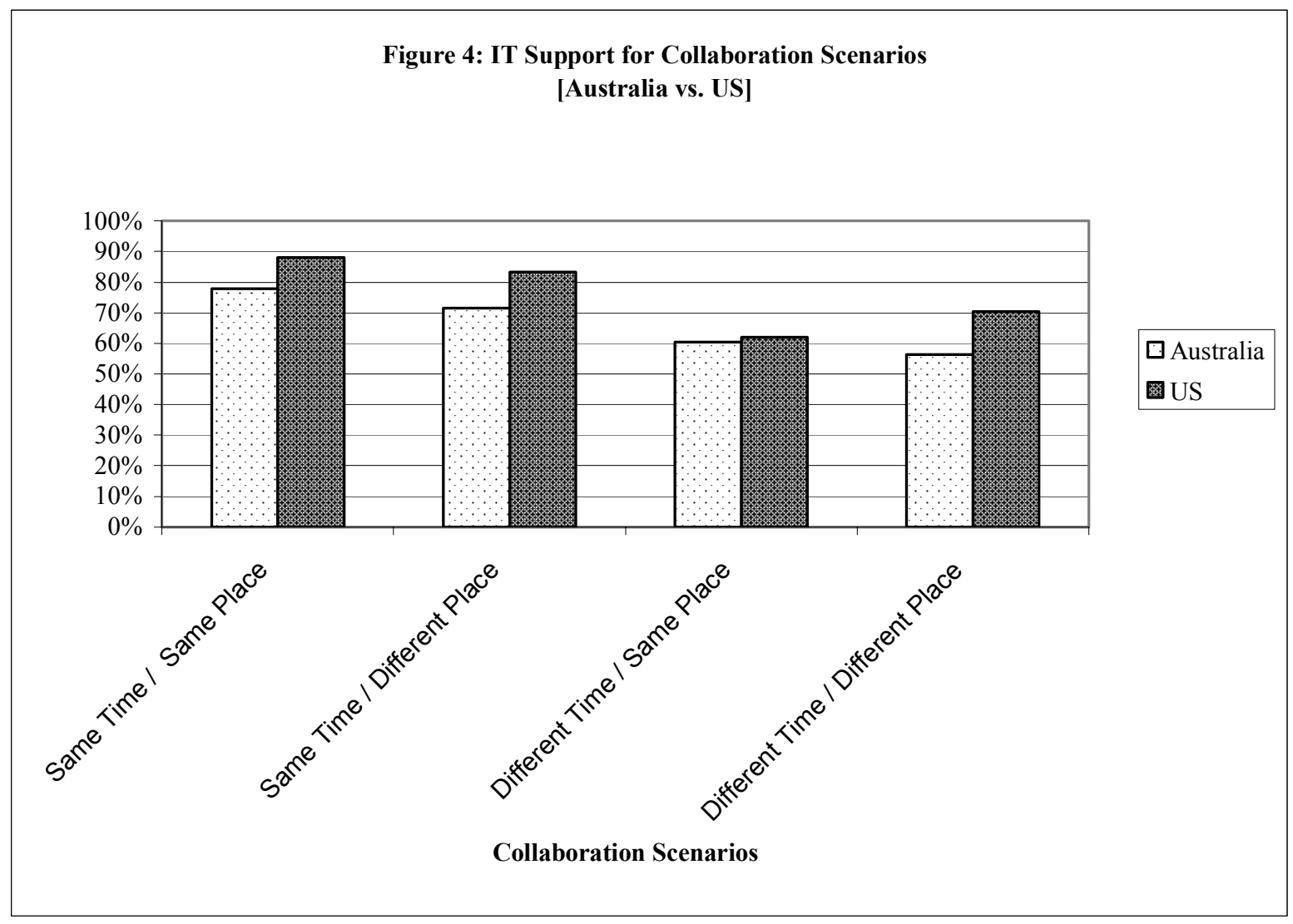

Table 2: Chi-square Analysis of IT Support for Collaboration Scenarios

\begin{tabular}{|c|c|c|c|c|c|}
\hline \multirow[b]{2}{*}{ Collaboration Scenarios } & \multirow[t]{2}{*}{ Current Practice } & \multicolumn{2}{|l|}{ Country } & \multicolumn{2}{|c|}{ Pearson Chi-Square } \\
\hline & & Australia & US & Value & Significance \\
\hline \multirow[t]{2}{*}{$\begin{array}{l}\text { Same Time / } \\
\text { Same Place }\end{array}$} & Yes & $\begin{array}{l}106 \\
{[77.9 \%]}\end{array}$ & $103[88 \%]$ & \multirow[t]{2}{*}{4.46} & \multirow[t]{2}{*}{$0.035^{* *}$} \\
\hline & No & $\begin{array}{l}30 \\
{[22.1 \%]}\end{array}$ & $\begin{array}{l}14 \\
{[12 \%]}\end{array}$ & & \\
\hline \multirow[t]{2}{*}{$\begin{array}{l}\text { Same Time / } \\
\text { Different Place }\end{array}$} & Yes & $\begin{array}{l}96 \\
{[71.6 \%]}\end{array}$ & $\begin{array}{l}95 \\
{[83.3 \%]}\end{array}$ & \multirow[t]{2}{*}{4.76} & \multirow[t]{2}{*}{$0.029^{* *}$} \\
\hline & No & $\begin{array}{l}38 \\
{[28.4 \%]}\end{array}$ & $\begin{array}{l}19 \\
{[16.7 \%]}\end{array}$ & & \\
\hline \multirow[t]{2}{*}{$\begin{array}{l}\text { Different Time / } \\
\text { Same Place }\end{array}$} & Yes & $\begin{array}{l}81 \\
{[60.4 \%]}\end{array}$ & $\begin{array}{l}70 \\
{[61.9 \%]}\end{array}$ & \multirow[t]{2}{*}{0.58} & \multirow[t]{2}{*}{0.81} \\
\hline & No & $\begin{array}{l}53 \\
{[39.6 \%]}\end{array}$ & $\begin{array}{l}43 \\
{[38.1 \%]}\end{array}$ & & \\
\hline \multirow[t]{2}{*}{$\begin{array}{l}\text { Different Time / } \\
\text { Different Place }\end{array}$} & Yes & $\begin{array}{l}76 \\
{[56.3 \%]}\end{array}$ & $\begin{array}{l}78 \\
{[70.3 \%]}\end{array}$ & \multirow[t]{2}{*}{5.08} & \multirow[t]{2}{*}{$0.024^{* *}$} \\
\hline & No & $\begin{array}{l}59 \\
{[43.7 \%]}\end{array}$ & $\begin{array}{l}33 \\
{[29.7 \%]}\end{array}$ & & \\
\hline
\end{tabular}


To investigate adoption of each IT cluster, we categorized all responses into two groups. Organizations that indicated no availability or access to a specific IT for anyone in the organization were categorized as nonadopters of that IT. On the other hand, an organization where a specific IT was available and accessible to any of its end-users was labeled as an adopter of that IT.

Figure 5 shows the pattern of adoption of the seven clusters in Australian and US organizations while table 3 shows the results of chi-square analysis between adopters and non-adopters of each IT in Australian and US organizations. There were significant differences in the proportion of organizations adopting four of the seven ITs (teleconferencing, videoconferencing, dataconferencing, and web-based tools) between Australian and US organizations, with a greater proportion of US organizations adopting these technologies.

\section{Discussion and conclusions}

The need to collaborate, synchronously or asynchronously, to accomplish tasks is gaining tremendous popularity in modern organizations. More and more organizations are tapping on the capabilities of IT to support task-oriented collaboration. However, there is a paucity of large-scale empirical investigations addressing this phenomenon at the macro level. Is collaboration being promoted in organizations? Is IT support being provided to support different collaboration scenarios? What are the patterns of adoption of IT to support task-oriented collaboration? Which ITs have been most widely adopted and which ones have low adoption? These are significantly important questions but historically we have had few answers that can be generalized across organizations.

Figure 5: Adoption of IT for Collaboration Support

[Australia vs. US]

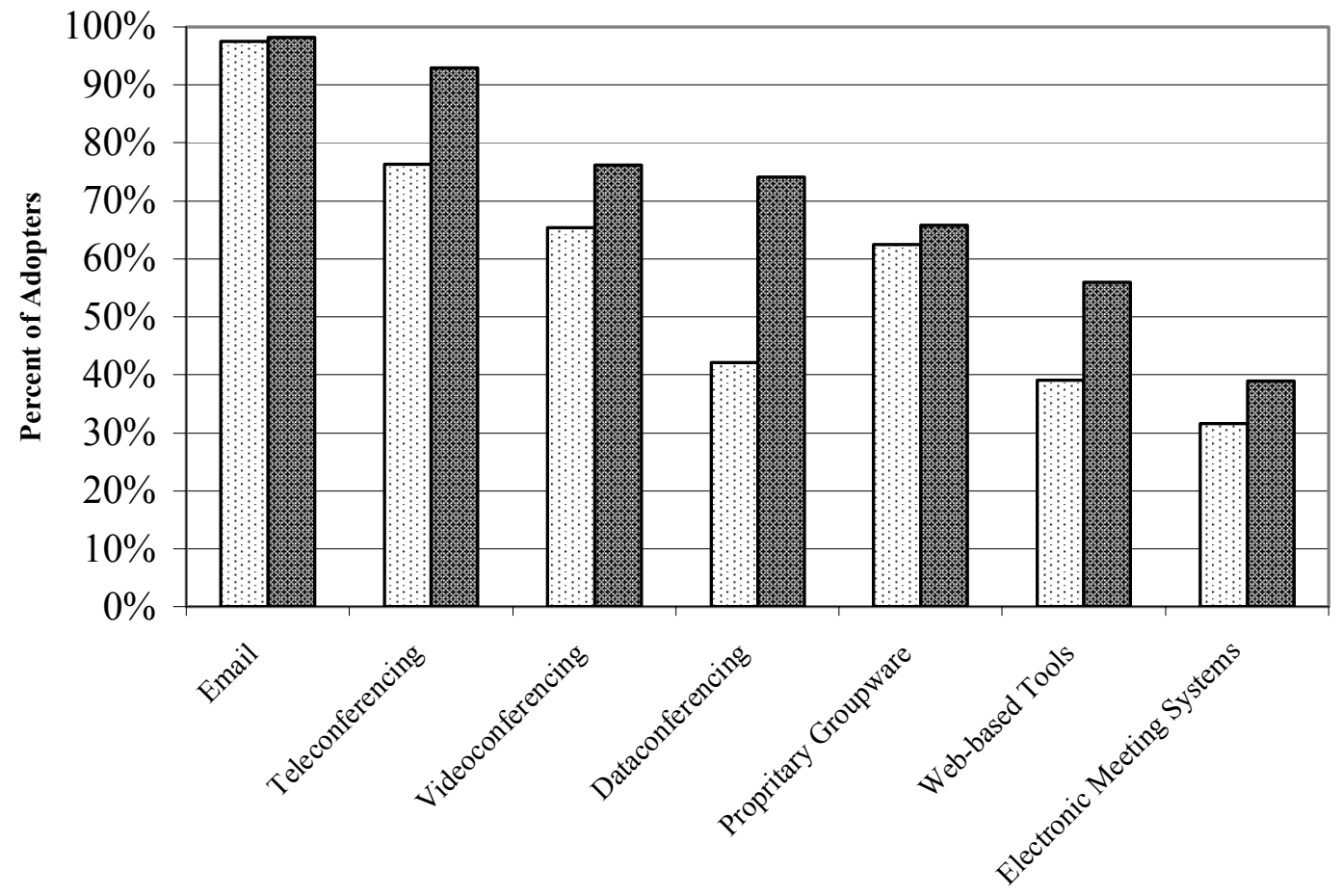

IT Cluster 
Table 3: Chi-square Analysis Between IT Adopters and Non-Adopters

\begin{tabular}{|c|c|c|c|c|c|}
\hline \multirow[t]{2}{*}{ Collaborative IT } & \multirow[t]{2}{*}{ Adoption Status } & \multicolumn{2}{|l|}{$\begin{array}{l}\text { Country } \\
\end{array}$} & \multicolumn{2}{|c|}{ Pierson Chi-Square } \\
\hline & & Australia & US & Value & Significance \\
\hline \multirow[t]{2}{*}{ E-mail } & A & $\begin{array}{l}116 \\
{[97.5 \%]}\end{array}$ & $\begin{array}{l}111 \\
{[98.2 \%]}\end{array}$ & \multirow[t]{2}{*}{0.15} & \multirow[t]{2}{*}{0.694} \\
\hline & NA & $\begin{array}{l}3 \\
{[2.5 \%]}\end{array}$ & $\begin{array}{l}2 \\
{[1.8 \%]}\end{array}$ & & \\
\hline \multirow[t]{2}{*}{ Teleconferencing } & A & $\begin{array}{l}90 \\
{[76.3 \%]}\end{array}$ & $\begin{array}{l}105 \\
{[92.9 \%]}\end{array}$ & \multirow[t]{2}{*}{12.16} & \multirow[t]{2}{*}{$0.000^{* * *}$} \\
\hline & NA & $\begin{array}{l}28 \\
{[23.7 \%]}\end{array}$ & $\begin{array}{l}8 \\
{[7.1 \%]}\end{array}$ & & \\
\hline \multirow[t]{2}{*}{ Videoconferencing } & A & $\begin{array}{l}77 \\
{[65.3 \%]}\end{array}$ & $\begin{array}{l}86 \\
{[76.1 \%]}\end{array}$ & \multirow[t]{2}{*}{3.27} & \multirow[t]{2}{*}{$0.070^{*}$} \\
\hline & NA & $\begin{array}{l}41 \\
{[34.7 \%]}\end{array}$ & $\begin{array}{l}27 \\
{[23.9 \%]}\end{array}$ & & \\
\hline \multirow[t]{2}{*}{ Dataconferencing } & A & $\begin{array}{l}48 \\
{[42.1 \%]}\end{array}$ & $\begin{array}{l}80 \\
{[74.1 \%]}\end{array}$ & \multirow[t]{2}{*}{23.21} & \multirow[t]{2}{*}{$0.000 * * *$} \\
\hline & NA & $\begin{array}{l}66 \\
{[57.9 \%]}\end{array}$ & $\begin{array}{l}28 \\
{[25.9 \%]}\end{array}$ & & \\
\hline \multirow[t]{2}{*}{ Web-based Tools } & A & $\begin{array}{l}43 \\
{[39.1 \%]}\end{array}$ & $\begin{array}{l}61 \\
{[56 \%]}\end{array}$ & \multirow[t]{2}{*}{6.25} & \multirow[t]{2}{*}{$0.012 * *$} \\
\hline & NA & $\begin{array}{l}67 \\
{[60.9 \%]}\end{array}$ & $\begin{array}{l}48 \\
{[44 \%]}\end{array}$ & & \\
\hline \multirow[t]{2}{*}{ Proprietary Groupware } & A & $\begin{array}{l}73 \\
{[62.4 \%]}\end{array}$ & $\begin{array}{l}73 \\
{[65.8 \%]}\end{array}$ & \multirow[t]{2}{*}{0.28} & \multirow[t]{2}{*}{0.596} \\
\hline & NA & $\begin{array}{l}44 \\
{[37.6 \%]}\end{array}$ & $\begin{array}{l}38 \\
{[34.2 \%]}\end{array}$ & & \\
\hline \multirow[t]{2}{*}{ Electronic Meeting Systems } & A & $\begin{array}{l}36 \\
{[31.6 \%]}\end{array}$ & $\begin{array}{l}42 \\
{[38.9 \%]}\end{array}$ & \multirow[t]{2}{*}{1.30} & \multirow[t]{2}{*}{0.254} \\
\hline & NA & $\begin{array}{l}78 \\
{[68.4 \%]}\end{array}$ & $\begin{array}{l}666 \\
961.1 \%]\end{array}$ & & \\
\hline
\end{tabular}

In this paper, we have attempted to fill this void by exploring these issues between Australian and US organizations. Our intent is to continue to expand our research to other regions of the globe and effort is already underway to accomplish our agenda. For this present paper, there were three primary objectives. The first objective was to provide insights into the promotion of collaboration in Australian and US organizations. Our results suggest that collaboration is important and managers/executives who responded to our survey reported that organizations in both Australia and the US are promoting collaboration in some important ways. For example, respondents from both countries perceive top management support for intra- and inter-organizational collaboration. The mean response from US managers/executives also indicated increasing use of virtual teams for collaboration, while the mean response from Australian managers/executives was neutral on this issue. Despite the apparent promotion of collaboration, respondents did not agree that there was a formal position in the organization with responsibility for managing collaboration. This lack of an internal "collaboration champion" may help account for some low adoption rates for certain information technologies, especially if they are more complex or expensive than others. In general, the managers/executives from US organizations were more likely to agree that collaboration was being promoted than the respondents from Australian organizations. It is also clear that there are significant regional (country) differences in mean levels of promotion of collaboration in organizations. US organizations are promoting collaboration to greater levels than their Australian counterparts.

The second objective was to explore IT support for four different collaboration scenarios. The majority of the respondents reported that their organizations were using IT to support collaboration in all of the time / place scenarios. Same Time / Same Place collaboration is most commonly supported, with nearly $90 \%$ of US respondents and almost $80 \%$ Australian respondents reporting support for this type of collaboration. The other scenarios are less commonly supported. Different Time / Same Place collaboration received the least IT support in US organizations while Different Time / Different Place 
collaboration are least supported by some type of IT in Australian organizations.

While all collaboration scenarios appear to be supported by IT to quite an extent, our findings suggest that IT support for Same Time / Same Place collaboration, Same Time / Different Place collaboration, and Different Time / Different Place collaboration is not independent of region (country). A significantly greater proportion of US organizations indicated IT support for these three collaboration scenarios than their Australian counter parts. This parallels our earlier finding that US organizations generally promote collaboration to a greater extent than Australian organizations.

The third objective was to investigate the patterns of adoption of ITs to support task-oriented collaboration. Our results suggest that there are some similarities in adoption patterns across the two countries. Within each country, E-mail, audio teleconferencing, and videoconferencing technologies had high adoption rates, while EMS had the lowest adoption rate. However between countries, there are large differences reported in the adoption of dataconferencing (US organizations reported a 74\% adoption rate while Australian organizations reported only a $42 \%$ adoption rate) and web-based tools (56\% adoption rate for US organizations versus 39\% for Australian organizations).

A further analysis between the two populations found no significant differences in the proportion of organizations adopting e-mail, proprietary groupware systems, and EMS. However, there were significant differences in the proportion of organizations between Australia and US as they relate to the adoption of the remaining ITs. A greater proportion of US organizations indicated adoption of audio teleconferencing, videoconferencing, data conferencing, and web-based tools than their Australian counterparts. It is possible that differences in the adoption of some of these ITs between the two countries could be explained by the differences in availability of resources. For example, further analysis (not reported earlier) of data indicated that total revenues of an organization (irrespective of region) are significantly related to adoption of videoconferencing, dataconferencing, proprietary groupware systems, and EMS. We also found total IT budgets to be significantly related to the adoption of all ITs except for the adoption of e-mail and web-based tools. There were more large organizations in the US sample and the IT function size also tended to be larger. This may indicate greater resources were available to support some of the more complex technologies. Perhaps the generally higher costs associated with teleconferencing and videoconferencing in Australia could also explain differences in adoption rates of these technologies in that country. However, the resource based perspective does not explain differences in adoption of web-based tools between Australian and US organizations. It may be possible that large differences in adoption of web-based tools could be due to differences in the availability of high-speed data lines in the two countries. The resource based view also does not explain no significant differences in the adoption of complex and relatively expensive proprietary groupware systems and EMS between Australian and US organizations.

While this research adds to the existing body of knowledge in the area of IT support for collaboration, there are nevertheless some limitations. First, this is only a snapshot of IT adoption at one point in time. We really cannot yet discuss how these patterns of adoption emerged and are changing over time. Second, a single respondent was used to collect data from each organization. However, the position of our respondents (the majority were top level executives and high ranking IT managers) lends creditability to the study. Given the organizational level focus of our research, we can certainly argue that these respondents are likely to be knowledgeable about IT adoption patterns to support task-oriented collaboration in their respective organizations. Third, our study focused only on Australian and US organizations. Given the attention on global business environments, this comparative analysis falls short when we consider macrolevel diffusion of IT to support collaboration in modern organizations. The study needs to be extended to other regions to provide a truly global perspective and every effort is being made towards that end.

Despite the above limitations, there are several implications for practice and research. For practitioners, our findings provide a benchmark to map their own organization's status of adoption of collaborative ITs. Using IT to collaborate and communicate effectively and efficiently amongst organizational members provides advantages that can have a significant positive impact on profitability and competitive position [2]. Thus, organizations on the lower end of the adoption spectrum of various ITs may be at a competitive disadvantage. Managers in these organizations should consider expending greater efforts promoting collaboration and acquiring appropriate IT that can support task-oriented collaboration amongst their employees. Furthermore, managers of multinational organizations planning to expand their operations to Australia can compare the relative adoption of ITs and make more informed decisions about IT support infrastructure for global collaborative efforts in their organizations.

For researchers, the study opens up many questions for future investigation of IT support for task-oriented collaboration. Why are some ITs adopted to a greater extent than others within a region (country)? Are adoption patterns associated with the maturity of IT, cost and complexity of IT, effectiveness of the IT to support collaboration, and/or functional capabilities of the IT? Which IT can better support which collaborative tasks? 
Which of these technologies are complementary and tend to be used together to support collaboration and which substitute for each other? Why do IT adoption patterns vary between regions (countries)? Are these due to differences in culture, country infrastructure, and/or lag effects of IT diffusion? These are just some of questions that need to be addressed by future investigations.

In conclusion, we have tried to address the macro-level adoption of seven clusters of IT to support collaboration. We certainly know that collaboration is seen as an important issue and is being promoted in organizations, to a greater level in the US as compared to Australia. IT support for collaboration is also popular, irrespective of region. Virtually all organizations in both the samples reported the adoption of some form of IT for collaboration support. However, some specific IT clusters have been adopted more widely in the US than in Australia.

While this paper reports on adoption vs. non-adoption patterns, it does not address the level of adoption of IT (the extent to which it is available and accessible in an organization), which could provide even richer insights into IT support for collaboration. The reason for the exclusion of such an analysis was purely due to the focused scope and size limitations of this paper. Moreover, although we have collected data on several predictors of IT adoption, comparing those predictors between Australian and US organizations were also beyond the scope of the present paper and will be pursued in other manuscripts.

\section{References}

[1] Anderson, J \& Kincaid-Yoshikawa, C. (1999). Case study: The evolution of electronic collaboration at Weyerhaeuser. http://www.collaborate.com/publications/ August 16.

[2] Bharadwaj, A. S. (2000). A resource-based perspective on information technology capability and firm performance: an empirical investigation. MIS Quarterly, 24(1), 169-196.

[3] Cheng, E.W., Li, H., Love, P.E., \& Irani, Z. (2000). Network communication in the construction industry, Corporate Communications: An International Journal, 6(2), 61-70.

[4] Daft, R. L. \& Lengel, R. H. (1986). Organization information requirements, media richness, and structural design. Management Science, 32(5), 554-571.

[5] Debra, D. L. \& Snyder, N. T. (1999). Mastering Virtual Teams. San Francisco, CA: Jossey-Bass Publishers.

[6] Dennis, A. (1996). Groupware on the web. Proceedings of the Tools and Methods for Business Engineering Conference, Washington DC, 573-581.

[7] Dennis, A.R., Pootheri, S.K., \& Natarajan, V.L. (1998). Lessons from the early adopters of web groupware. Journal of Management Information Systems, 14, 65-86.
[8] Jessup, L. (2000). Mastering virtual teams: Strategies, tools, and techniques that success. Book review in Small Group Research, 31, 245-248.

[9] Jessup, L., \& Valacich, J. (Eds.) (1993). Group Support Systems: New Perspectives. New York: Macmillan Publishing Company.

[10] Kettinger, W.J., \& Grover, V. (1997). The use of computermediated communication in an interorganizational context. Decision Sciences, 28(3), 513-555.

[11] Kirkpatrick, D. (1993). Groupware goes boom. Fortune, December 27, 99-106.

[12] Laudon, Kenneth \& Laudon, Jane. (2001). Essentials of Management Information Systems. $4^{\text {th }}$ Edition. Upper Saddle River, New Jersey: Prentice Hall,.

[13] Lewis, L.F., Garcia, J.E., \& Keleman, K. (2000). Continuing obstacles and new opportunities for organizational adoption of GSS. Presented at Group Decision and Negotiation Conference, University of Strathclyde, Glasgow, Scotland, July $3-7,2000$.

[14] Ozer, M. (1999). The use of Internet-based groupware in new product forecasting. International Journal of Market Research, 41(4), 425-435.

[15] Pervan, G.P. (1998). A review of research in group support systems: Leaders, approaches and directions. Decision Support Systems, 23, 149-159.

[16] Pervan, G.P. (1998b). How chief executive officers in large organizations view the management of their information systems. Journal of Information Technology, 13, 95-109.

[17] Sethi, V. and W. R King, W.R. (1991). Construct measurement in information systems research: an illustration in strategic systems. Decision Sciences, 22(3), 455-472.

[18] Slyke, C. V., H. Lou, and J. Day. (2002). The impact of perceived innovation characteristics on intention to use groupware. Information Resource Management Journal 15(1), $5-12$.

[19] Straub, D. W., Jr., R. A. Beauclair. (1988). Current and future uses of group decision support system technology: report on a recent empirical study. Journal of Management Information Systems, 5(1), 101-116.

[20] Tung, L. \& Turban, E. (1998). A proposed research framework for distributed group support systems. Decision Support Systems, 23, 175-188.

[21] Turoff, M., Hiltz, S.R., Bahgat, A.N., \& Rana, A.R. (1993). Distributed group support systems. MIS Quarterly, 17, 399-417.

[22] Ward, L. (1999). Collaborative commerce at Cisco. http://www.collaborate.com/publications/ August 16. 